УДК 811.133.1

ББК 81.471.1

DOI: https://doi.org/10.17308/lic.2020.2/2846

\title{
КАТЕГОРИЯ ИНСТРУМЕНТАЛЬНОСТИ В ИНТЕРЯЗЫКЕ (ФРАНЦУЗСКОМ) ИСКУССТВЕННЫХ МУЛЬТИЛИНГВОВ
}

\author{
Н. В. Лосева, Т. В. Брагина
}

Московский государственный институт международных отночений (университет) МИД России

\section{THE CATEGORY OF INSTRUMENTALITY IN FRENCH INTERLANGUAGE OF MULTILIGUAL STUDENTS}

\author{
N. V. Loseva, T. V. Bragina \\ Moscow State Institute of International Relations
}

\begin{abstract}
Аннотация: интерязык искусственных мультилингвов испытывает двойное воздействие родного и первого иностранного языков как на глубинном, так и на поверхностном уровнях. В данной статье предпринята попытка описать влияние русского и английского языков на формирование категории инструментальности в интерязыке (франиузском). В основе исследования лежит эксперимент, в котором приняли участие студенты МГИМО, изучающие франиузский язык после английского. Функионально-семантическое поле инструментальности в русском языке моночентрично, его ядром является творительный падеж. В английском же языке аналогичное поле бичентрично и имеет в качестве ядра предлоги by и with. Анализ результатов эксперимента позволил авторам прийти к выводу о том, что для языкового сознания искусственного мультилингва характерно доминирование родного языка на глубинном уровне. Слабая дифференцированность субкатегорий орудия, средства и способа действия, которые в русском языке единообразно выражаются творительным падежом, приводит к неразличению этих значений в интерязыке. Интерферирующее воздействие английского языка наблюдается на поверхностном уровне, затрагивая механизм выбора маркера инструментальных отношений. Искусственный мультилингв неосознанно находит эквивалентные маркеры в двух языках и абсолютизирует эту эквивалентность. Процесс выявления «зеркальных» маркеров усиливается отсутствием дифференцирующего маркера в родном языке, в результате чего английский язык становится формальной опорой для дифференциации. Тенденџия к эксплицитности, свойственная интерязыку, усиливает роль отдельных маркеров, например, предлога par, который интуитивно воспринимается как полный эквивалент русского творительного падежа и как наиболее яркий маркер отношений инструментальности.
\end{abstract}

Ключевые слова: интерязык, мультилингвизм, языковое сознание, интерференция, категория инструментальности, глубинный падеж.

Abstract: the interlanguage of artificial multilinguals experiences the influence of their native language and first foreign language both at deep and superficial levels. This article attempts to describe the impact of Russian and English on the instrumental meaning expression in French interlanguage. The research is based on the experiment which involved students of MGIMO university learning French as a second foreign language after English. The functional and semantic field of instrumentality in Russian is monocentric and its nucleus is formed by the instrumental case. In English the same field has two prepositions as its core: with and by. The experiment results have led the authors to the conclusion that native language dominates language mentality at the deep level. The fact that such meanings as "instrument", "means", "way of doing" have weak differentiation in Russian results in non-differentiation of those meanings in French interlanguage. The interfering influence of the English language is observed at the superficial level as it affects the choice of a relation marker. Multilingual students would try to find equivalent markers in two languages and then to absolutize this equivalence. While there is no difference in

(C) Лосева Н. В., Брагина Т. В., 2020

Контент доступен под лицензией Creative Commons Attribution 4.0 License.

The content is available under Creative Commons Attribution 4.0 License. 
native language, first foreign language becomes a basis for differentiation. The tendency to an explicit way of expressing relations (characteristic of any interlanguage) increases the importance of certain markers, for example, the preposition par, which is perceived by multilingual students as a full equivalent of Russian instrumental case and the best way to express instrumental meaning.

Key words: interlanguage, multilingualism, language mentality, interference, category of instrumentality, deep case.

\section{Теоретическое введение}

Повышенный интерес к процессу овладения иностранным языком, а также к механизмам естественного и искусственного билингвизма определяет актуальность исследований в области интерязыка. Под интерязыком (или промежуточным/переходным языком) обычно имеют в виду языковую систему и речевой код, которые складываются в языковом сознании изучающего иностранный язык. Эта система отлична от языка носителей. Она подвижна и представляет собой континуум, «по которому последовательно продвигается обучающийся» [1, с. 302] на пути приближения своего индивидуального языка к языку естественному. Будучи вторичным по своей природе, интерязык в процессе своего становления подвергается воздействию других языков (родного и иностранных), ранее закрепившихся в языковом сознании индивида. Таким образом, интерязык становится доступной непосредственному наблюдению сферой языковых контактов, что во многом объясняет интерес ученых к этому лингвистическому конструкту, который все чаще становится самостоятельным объектом исследования наряду с естественными языками.

Когда мы говорим о воздействии других языков на вновь изучаемый язык, мы, естественно, не имеем в виду, что структуры интерязыка являются прямым переводом, либо калькой со структур родного (РЯ) или первого иностранного (ИЯ1) языков. Интерязык представляет собой продукт мультилингвального языкового сознания в том смысле, что он формируется в окружении других языков, используя общие речемыслительные механизмы. Язык отражает внеязыковую реальность. Значит ли это, что каждый язык в сознании мультилингва образует отдельные специфические связи с реальностью? Говоря о связи предметной ситуации со структурой высказывания, Г. А. Золотова отмечает, что «структуру ситуации, ее членение мы представляем лишь так, как она отражена в нашем языковом сознании» [2, с. 17]. Это означает, что в речи фиксируется не собственно предметная ситуация, а привычный способ ее концептуализации. Констатируя наличие у разных языков, составляющих языковое сознание индивида, общей предметно-семантической базы на довербальном уровне, хочется согласиться с мнением А. В. Бондарко, который отмечает, что «эквивалентность смыслового содержания, лежащая в основе языкового содержания "равнозначных" высказываний в со- поставляемых языках, сочетается с возможной или неизбежной неэквивалентностью языковой интерпретации. Иначе говоря, существует эквивалентность на уровне глубинной семантики и неэквивалентность на уровне семантики поверхностной» [3, с. 113]. Очевидно, что доминирующим на глубинном уровне языкового сознания является родной язык. Но естественным было бы предположить, что каждый новый язык, привнося в арсенал индивида новые модели поверхностных структур, постепенно начинает воздействовать и на глубинные уровни, расширяя и модифицируя языковое сознание. Таким образом, языковое сознание пронизано разнонаправленными взаимодействиями: горизонтальными (между разными языковыми системами) и вертикальными (связывающими уровни глубинных и поверхностных структур). В рамках лингводидактических исследований взаимное влияние языковых систем обычно определяют термином «интерференция». Под интерференцией часто понимают отрицательное воздействие РЯ или ИЯ1, ведущее к ошибке. Нам уже приходилось отмечать, что суженное понимание интерференции как отрицательного переноса навыков, тормозящего процесс освоения нового языка, контрпродуктивно в научной перспективе. И напротив, углубленное изучение межязыковых взаимодействий открывает доступ к глубинным уровням языкового сознания [4].

Изучая интерязык, исследователи зачастую концентрируют свое внимание на ошибках обучающихся. И это неудивительно, поскольку именно сбой системы позволяет увидеть скрытые механизмы ее функционирования. Именно ошибки маркируют основные отличия интерязыка от естественного языка носителей. Однако этот подход не стоит абсолютизировать. Зачастую и правильная форма или синтаксическая модель занимают в интерязыке место, отличное от того, которое им принадлежит в естественном языке, а появление этой формы в речи обучающегося может быть инициировано иными механизмами, нежели те, которые действуют в языке носителей. Поэтому изучению подлежит вся структура интерязыка как переходной языковой системы и переходного речевого кода.

В нашем исследовании мы обращаемся к ситуации искусственного учебного мультилингвизма. Объектом наших наблюдений являются русскоязычные студенты, изучающие французский язык в университете. При этом первым иностранным языком 
для них является английский. Предметом нашего исследования стала категория инструментальности в интерязыке (французском).

Инструментальность представляет собой один из базовых универсальных концептов, входящих в языковое сознание на довербальном предметно-семантическом уровне. Инструмент является неотъемлемой частью любой человеческой деятельности, и поэтому отношения инструментальности неизбежно находят выражения в разных типах поверхностных структур во всех языках. Категория инструментальности неоднородна и включает в себя ряд субкатегорий, связанных с обозначением орудия, средства, посредника, способа совершения действия и др. При этом А. В. Кобцева справедливо замечает, что исследование категории инструментальности тесно связано с изучением глубинного и поверхностного падежа, «поскольку в качестве наиболее распространенного средства выражения инструментального значения выступает падеж» [5, с. 11]. В русском языке в этом качестве выступает творительный падеж, который является центральным элементом функционально-семантического поля (ФСП) инструментальности.

Поскольку ФСП инструментальности в русском языке «моноцентрично с морфологической категорией в центре» [6, с. 31], в лингвистической литературе оно неоднократно описывалось как в семасиологическом, так и в ономасиологическом ключе. В ряду работ, выполненных в рамках первого подхода, следует особо выделить исследование А. Вежбицкой, посвященное творительному падежу в русском языке. «Главная функция творительного падежа в русском языке - это, конечно, указание на орудие действия («инструмент»). Мы говорим, что эта функция главная, поскольку так предположительно следует из самого названия падежа: творительный, или инструментальный, падеж идентифицируется в любом языке как падеж, имеющий среди своих функций функцию обозначения инструмента», указывает автор [7, с. 312]. Выявляя существенные связи между глубинным и поверхностным падежом, А. Вежбицка выделяет следующие типы значений творительного падежа: инструмент (открыть дверь ключом), объект в предложениях со значением действия (швыряться камнями), действия, производимые частями тела (пожать плечами), место (идти полем), время (встретиться ночью), эмоция (гордиться сыном), стихийное воздействие (убило деревом), деятель в пассивной конструкции (окно разбито детьми), способ действия в предложениях со значением процесса (харкать кровью), сравнение (выть волком), образ действия (плакать горючими слезами), свойство (бледен лицуом), предикат (был титулярным советником). Как мы видим, не все из перечисленных значений имеют отношение к инструментальности. Тем не менее творительный падеж покрывает широкий круг значений, относящихся к орудию, средству, способу и образу действия, а также к агенсу (деятелю).

Рассуждая в ономасиологическом ключе, В. А. Белошапкова и Е. В. Муравенко прослеживают разные способы выражения инструментального значения в русском языке, при этом творительный падеж оказывается центральным, но не единственным средством выражения этого значения. Для целей нашего исследования принципиально важным представляется предлагаемое авторами разграничение инструмента (писать ручкой) и средства (писать чернилами). Авторы отмечают, что «формы со значением инструмента отличаются от форм со значением средства тем, что использование средства приводит к его расходованию, «связыванию», в то время как применение инструмента оставляет его в несвязанном состоянии» [8, с. 78]. Примечательно, что на поверхностном уровне эти два значения в русском языке не дифференцируются и находят одинаковое выражение в творительном падеже (писать ручкой - писать чернилами, сиить иголкой - сиить ниткой).

Анализируя поле инструментальности в английском языке, С. В.Бужинский подчеркивает, что падежные смыслы передаются в английском языке в основном с помощью предложных конструкций [6, c. 5]. Ядро ФСП инструментальности в английском языке составляют предлоги with и by. «При двуцентровой компоновке ФСП предлог with будет являться ядром микрополя “средство - предмет”, а предлог by будет находиться в центре субкатегории “средство непредмет". [...] Однако with специализируется на выражении не только зоны смыслов “средство - предмет”, но и широко используется при выражении “непредметного” средства, т. е. способа действия [6, c. 33]. Проводя сравнение с русским языком и основываясь на возможности применения категории “падеж” в ее глубинном смысле к структурам английского языка, исследователь выделяет творительный орудия, средства (материала), неотчуждаемого инструмента (части тела), стихийной силы, агенса (деятеля). В выделенных микрополях в качестве средств выражения инструментальности доминируют предлоги with и $b y$, хотя в отдельных значениях встречаются и другие предлоги (in, at, from и др.).

Исследователи грамматики французского языка приходят к выводу о том, что в центре ФСП инструментальности находятся предлоги avec и par. Отметим однако, что их функционирование для выражения различных инструментальных значений не является зеркальным отражением английских with и $b y$, несмотря на значительные сходства. «Собственно орудийное значение чаще всего выражается предлогом avec, который может употребляться практически перед любым конкретным существительным» [9, 
c. 106]. В. Г. Гак отмечает, что предлог par употребляется в основном с абстрактными существительными, предлог de - перед словами, обозначающими часть тела, $\grave{a}-$ в некоторых словосочетаниях при определенном артикле, avec - во всех остальных случаях [10, с. 294].

Не претендуя на углубленный лингвистический анализ и оставив в стороне многочисленные ситуационные и стилистические варианты, мы можем представить способы выражения основных инструментальных значений в русском, английском и французском языках в виде таблицы.

Из таблицы видно, что в ряде случаев имеет место «зеркальное» совпадение средств выражения инструментального значения во французском и английском языках. Французский предлог аvес кажется прямым аналогом английского with, а французский par - английского $b y$. Подобная «зеркальность» дает студентам, изучающим французский язык после английского, повод для абсолютизации этого сходства и параллельного переноса структур из английского языка во французский, что, естественно, становится источником ошибок в случаях, когда такого совпадения не наблюдается.

Следует также отметить, что ФСП инструментальности во всех трех языках включают деепричастие/герундий. При этом в английском языке герундий в инструментальном значении сопровождается предлогом $b y$, в то время как во французском языке gérondif включает в себя предлог еп и не может сочетаться с другими предлогами. Это несовпадение способов выражения инструментальности в двух языках становится источником многочисленных эмпирически наблюдаемых интерференционных оши- бок, когда в речи студентов возникает ошибочная конструкция * par faisant qch, не существующая в нормативном французском языке. Интересно также, что в речи студентов с достаточной частотой возникает столь же ошибочная конструкция * par faire qch, которая не имеет прямых аналогов ни в русском, ни в английском языках и должна быть квалифицирована как оригинальный конструкт интерязыка. Ее возникновение можно объяснить косвенным интерференционным воздействием английского языка, допускающего сочетания предлога $b y$ с глагольной формой, абсолютизацией инструментального значения предлога par в языковом сознании обучающегося и неудачной попыткой создать допустимую по нормам языка (инфинитив во французском языке сочетается с предлогом) гибридную конструкцию.

Мы проверили наше предположение об абсолютизации инструментального значения предлога par, проведя небольшой опрос среди русскоязычных преподавателей французского языка. Отвечая на вопрос «Какие из французских предлогов передают значения русского творительного падежа?», 80 \% респондентов указали предлог раr. При этом предлоги avec и de были указаны в 20 и 30 \% ответов соответственно. Мысль о приоритетной роли предлога par в системе средств выражения значений, опосредуемых в русском языке творительным падежом, подтверждается и мнениями лингвистов. Так В. Г. Гак, сопоставляя русскую падежную и французскую предложные системы, отмечает: «Во французской речи предлоги употребляются в полтора раза чаще, чем в русской, что объясняется прежде всего следующими конкретными случаями: употребление $d e$ в именной группе (рус. родительный падеж), $\grave{a}$ и

Т а б ли ц а

Способы выражения основных инструментальных значений

\begin{tabular}{|l|c|c|}
\hline \multicolumn{1}{|c|}{ Русский язык } & Английский язык & Французский язык \\
\hline $\begin{array}{l}\text { Творительный орудия } \\
\text { открыть ключом }\end{array}$ & with \\
\hline $\begin{array}{l}\text { Творительный средства (материала) } \\
\text { сшить ниткой }\end{array}$ & with / in \\
\hline $\begin{array}{l}\text { Творительный неотчуждаемого инструмента (части } \\
\text { тела) } \\
\text { показать рукой }\end{array}$ & with & de / avec \\
\hline $\begin{array}{l}\text { Творительный стихийной силы } \\
\text { дарило молнией }\end{array}$ & par \\
\hline $\begin{array}{l}\text { Творительный агенса } \\
\text { селано мастером }\end{array}$ & by \\
\hline $\begin{array}{l}\text { Творительный средства связи или передвижения } \\
\text { пиехать поездом }\end{array}$ & by & par / en \\
\hline $\begin{array}{l}\text { Способ действия } \\
\text { стирать руками / вручную }\end{array}$ & by & à \\
\hline
\end{tabular}


par в значении дательного и творительного падежей...» [11, с. 169]. Парадоксальным образом крупнейший российский лингвист, основатель школы сопоставительного изучения французского и русского языков в данном случае высказывает интуитивное суждение, свидетельствующее о том, что для руссофонов, изучающих французский язык и говорящих на нем, именно предлог par выступает в качестве прототипического маркера глубинного творительного падежа.

Таким образом, можно предположить, что на формирование категории инструментальности в интерязыке (французском) искусственных мультилингвов оказывают воздействие несколько факторов. Во-первых, слабая дифференцированность плана выражения в русском языке создает почву для смешения, ошибочного употребления конструкций с предлогами par, avec, de, à, en. Во-вторых, влияние английского языка может быть позитивным в случаях «зеркального» совпадения конструкций с предлогами by - par, with - avec и негативным в случаях отсутствия такого совпадения. В-третьих, на формирование ФСП инструментальности воздействует внутренняя логика интерязыка, в соответствии с которой некоторым маркерам отношений (предлогу раr в нашем случае) приписывается универсальный статус, и этот маркер начинает использоваться для создания конструкций, теоретически возможных, но не существующих в реальном языке. Для подтверждения этих гипотез нами было проведено экспериментальное исследование.

\section{Методика исследования}

В интерязыковых исследованиях применяются разные методы. Поскольку первыми исследователями интерязыка являются преподаватели, чаще всего они действуют методом наблюдения и фиксации ошибок, что безусловно является необходимым этапом работы, который дает возможность определить направления исследований и сформулировать рабочие гипотезы. Важным методом является работа с корпусами устных и письменных высказываний обучающихся. Но для получения надежных результатов объем корпусов должен быть достаточно большим, а состав респондентов относительно однородным, что трудно достижимо. В нашей работе мы использовали метод направленного эксперимента. Недостатком этого метода является отсутствие спонтанности в речевых реакциях респондентов, но к его достоинствам следует отнести объективность и верифицируемость.

\section{Описание эксперимента}

В роли респондентов в нашем эксперименте выступили студенты МГИМО, изучающие французский язык (всего 66 человек). Родным языком (РЯ) для всех испытуемых является русский, первым иностранным (ИЯ1) - английский, а вторым иностранным (ИЯ2) французский. Уровень владения ИЯ1 можно условно определить как В2, а ИЯ2 как В1 по общеевропейской классификации. Естественно, что степень владения иностранными языками отдельных испытуемых может различаться, но все они находятся в пределах одного уровня. Респонденты были разделены на две группы (по 33 человека в каждой). Первой группе были предложены для перевода фразы, содержащие структуры с разными типами инструментальных значений с ИЯ1 на ИЯ2. Таким образом испытуемые этой группы были искусственно поставлены в условия индуцированной интерференции с английским языком. Второй группе предлагались аналогичные фразы для перевода с РЯ на ИЯ2, т. е. для этой группы респондентов интерференция с ИЯ1 была латентной. Варианты перевода аналогичных структур в двух группах подвергались затем сравнению и анализу.

\section{Результаты эксперимента}

Структура 1. Орудие

\begin{tabular}{|lr|lr|}
\hline \multicolumn{2}{|c|}{$\begin{array}{c}\text { английский } \rightarrow \\
\text { французский }\end{array}$} & русский $\rightarrow$ французский \\
\hline $\begin{array}{l}\text { I can't open this door with } \\
\text { my key. }\end{array}$ & $\begin{array}{l}\text { Я не могу открыть эту } \\
\text { дверь своим ключом. }\end{array}$ \\
\hline avec (корректно) & $81 \%$ & avec (корректно) & $60 \%$ \\
\hline par & $15 \%$ & par & $30 \%$ \\
\hline иное & $4 \%$ & иное & $10 \%$ \\
\hline
\end{tabular}

Сравнение результатов по двум группам показывает, что ИЯ1 в данном случае становится основой для позитивного переноса, в то время как при переводе с РЯ существенно снижается число правильных ответов (с предлогом avec) и, напротив, в два раза увеличивается вероятность выбора предлога par, который, как мы уже отмечали, интуитивно воспринимается русскоговорящими как аналог творительного падежа.

Структура 2. Средство (материал)

\begin{tabular}{|c|c|c|c|}
\hline \multicolumn{2}{|l|}{$\begin{array}{c}\text { английский } \rightarrow \\
\text { французский }\end{array}$} & \multicolumn{2}{|c|}{ русский $\rightarrow$ французский } \\
\hline $\begin{array}{l}\text { The walls of the class } \\
\text { are decorated with pi } \\
\text { of Paris. }\end{array}$ & $\begin{array}{l}\text { room } \\
\text { ctures }\end{array}$ & $\begin{array}{l}\text { Стены кабинета были } \\
\text { украшены фотографı } \\
\text { Парижа. }\end{array}$ & иями \\
\hline de (корректно) + des & $54 \%$ & de (корректно) + des & $51 \%$ \\
\hline avec & $15 \%$ & avec & $12 \%$ \\
\hline par & $24 \%$ & par & $36 \%$ \\
\hline иное & $7 \%$ & иное & $11 \%$ \\
\hline
\end{tabular}

Респонденты обеих групп дают приблизительно равное число правильных ответов, которое в абсо- 
лютном выражении довольно невысоко. Заметим, что ошибки в употреблении артикля нами не учитывались. Распределение ответов между тремя предлогами демонстрирует большую неустойчивость, что позволяет сделать вывод об отсутствии четкой дифференциации значений орудие - средство - деятель.

Структура 3. Неотчуждаемый инструмент (часть тела)

\begin{tabular}{|c|c|c|c|}
\hline \multicolumn{2}{|c|}{$\begin{array}{c}\text { английский } \longrightarrow \\
\text { французский }\end{array}$} & \multicolumn{2}{|c|}{$\begin{array}{c}\text { русский } \rightarrow \\
\text { французский }\end{array}$} \\
\hline \multicolumn{2}{|c|}{$\begin{array}{l}\text { You should not eat with } \\
\text { your fingers. }\end{array}$} & \multicolumn{2}{|c|}{$\begin{array}{l}\text { В некоторых азиатских } \\
\text { ресторанах можно есть } \\
\text { руками. }\end{array}$} \\
\hline avec (корректно) & $58 \%$ & avec (корректно) & $55 \%$ \\
\hline par & $9 \%$ & par & $24 \%$ \\
\hline иное (à, de, en) & $33 \%$ & иное & $11 \%$ \\
\hline
\end{tabular}

Незначительное увеличение числа корректных ответов у испытуемых первой группы (несмотря на «зеркальное» совпадение предлогов в двух языках) свидетельствует о том, что интерференция не является механизмом прямого действия. Косвенное воздействие интерференции заметно в том, что меньшее число респондентов по сравнению со второй группой выбирают предлог раr, отдавая предпочтение десемантизированным предлогам $\grave{a}, d e, e n$.

Структура 4. Средство связи или передвижения

\begin{tabular}{|ll|lr|}
\hline \multicolumn{2}{|c|}{$\begin{array}{c}\text { английский } \rightarrow \\
\text { французский }\end{array}$} & \multicolumn{2}{c|}{$\begin{array}{c}\text { русский } \rightarrow \\
\text { французский }\end{array}$} \\
\hline Peter came by train. & $\begin{array}{l}\text { По Европе я } \\
\text { предпочитаю } \\
\text { путешествовать поездом. }\end{array}$ \\
\hline par (корректно) & $30 \%$ & par (корректно) & $9 \%$ \\
\hline en (корректно) & $66 \%$ & en (корректно) & $81 \%$ \\
\hline иное & $4 \%$ & иное & $10 \%$ \\
\hline
\end{tabular}

При указании на средство передвижения французский язык допускает несколько корректных вариантов, поэтому интерес здесь представляет исключительно распределение ответов между предлогами en и par, которое демонстрирует существенное, хотя и не определяющее интерференционное воздействие ИЯ1.

Структура 5. Способ

\begin{tabular}{|c|c|}
\hline $\begin{array}{c}\text { английский } \rightarrow \\
\text { французский }\end{array}$ & $\begin{array}{c}\text { русский } \rightarrow \\
\text { французский }\end{array}$ \\
\hline $\begin{array}{l}\text { Don't put the sweater in } \\
\text { the washing machine. It } \\
\text { has to be washed by hand. }\end{array}$ & $\begin{array}{l}\text { Вы можете написать } \\
\text { мотивационное письмо } \\
\text { от руки. }\end{array}$ \\
\hline à (корректно) + aux $12 \%$ & à (корректно) + aux $24 \%$ \\
\hline $33 \%$ & $33 \%$ \\
\hline $30 \%$ & $21 \%$ \\
\hline $25 \%$ & $22 \%$ \\
\hline
\end{tabular}

Крайне пестрая картина распределения ответов в обеих группах без заметного интерференционного воздействия ИЯ1 свидетельствует, по нашему мнению, о том, что субкатегории инструмента, средства и способа действия слабо дифференцированы в языковом сознании руссофонов. Характерно, что в обеих группах доминирует по числу употреблений предлог $p a r$, что подчеркивает его особое место среди средств выражения инструментальности.

Структура 6. Способ (герундий)

\begin{tabular}{|c|c|}
\hline $\begin{array}{c}\text { английский } \rightarrow \\
\text { французский }\end{array}$ & $\begin{array}{c}\text { русский } \rightarrow \\
\text { французский }\end{array}$ \\
\hline $\begin{array}{l}\text { Students can improve their } \\
\text { vocabulary by watching } \\
\text { American series online. }\end{array}$ & $\begin{array}{l}\text { Студенты могут } \\
\text { усовершенствовать свой } \\
\text { французский, регулярно } \\
\text { слушая радио. }\end{array}$ \\
\hline $\begin{array}{r}\text { en regardant (корректно) } \\
60 \%\end{array}$ & $\begin{array}{r}\text { en écoutant (корректно) } \\
72 \%\end{array}$ \\
\hline $\begin{array}{r}\text { par (+ gérondif /infinitif) } \\
24 \%\end{array}$ & $\begin{array}{r}\text { par (+ gérondif /infinitif) } \\
12 \%\end{array}$ \\
\hline $16 \%$ & иное \\
\hline
\end{tabular}

Распределение ответов между корректной структурой (герундий, включающий предлог en) и отсутствующими в нормативном французском языке структурами с предлогом par говорит о существенном интерференционном воздействии ИЯ1, где структуры с предлогом by специализированы на передаче инструментального значения. При этом некорректные структуры с предлогом par встречаются и в переводе с РЯ. Этот факт свидетельствует о том, что структуры с par, закрепившиеся в интерязыке под несомненным воздействием ИЯ1, функционируют в нем вне непосредственного контакта с источником интерференции. Кроме того, среди этих структур встречаются и конструкции «раr + инфинитив», которые не являются непосредственной калькой с английского, но вызваны к жизни, по всей вероятности, стремлением интерязыка к эксплицитности отношений. А универсальным маркером отношений инструментальности в интерязыке является, судя по всему, предлог par.

Структура 7. Авторство

\begin{tabular}{|c|c|c|c|}
\hline \multicolumn{2}{|c|}{$\begin{array}{c}\text { английский } \longrightarrow \\
\text { французский }\end{array}$} & \multicolumn{2}{|c|}{$\begin{array}{c}\text { русский } \rightarrow \\
\text { французский }\end{array}$} \\
\hline \multicolumn{2}{|c|}{$\begin{array}{l}\text { In this library you will find } \\
\text { a lot of stories by Jack } \\
\text { London. }\end{array}$} & \multicolumn{2}{|c|}{$\begin{array}{l}\text { Я прочел эту новеллу } \\
\text { Мопассана за один час. }\end{array}$} \\
\hline de (корректно) & $60 \%$ & de (корректно) & $75 \%$ \\
\hline par & $30 \%$ & par & $3 \%$ \\
\hline иное & $10 \%$ & иное & $22 \%$ \\
\hline
\end{tabular}

Эта структура была включена в наш вопросник в связи с тем, что она демонстрирует любопытный случай различия в трактовке отношений в разных 
языках. В английском языке связь между произведением и автором трактуется как отношение «объект агенс», в то время как в русском и французском это скорее отношение «объект - обладатель». Индуцированная интерференция с ИЯ1 в этой части эксперимента проявляется очень ярко. Число ответов par в первой группе в три раза выше, чем во второй. Однако и при переводе с РЯ в единичных случаях, но тем не менее, такой вариант ответа присутствует, что свидетельствует о том, что подобная интерпретация отношений между произведением и автором потенциально присутствует в языковом сознании мультилингва. Некоторое удивление вызывает большое число ответов, подпадающих под разряд «иное» во второй группе респондентов. Здесь приходится с огромной грустью констатировать, что некоторые студенты очевидно не поняли, что Мопассан - это писатель, а не название произведения.

\section{Выводы}

На основе проведенного исследования можно сделать следующие выводы.

1. Функционально-семантическая категория инструментальности является универсальной глубинной категорией языкового сознания. Говорящий на любом языке испытывает естественную потребность выражать инструментальные отношения и ищет адекватные средства их выражения.

2. Формирование специфически языковой категории инструментальности в интерязыке происходит под воздействием других языков, уже присутствующих в языковом сознании (РЯ и ИЯ1). Для языкового сознания искусственного мультилингва характерно доминирование родного языка на глубинном уровне в том смысле, что концепты, изначально опосредованные родным языком, с трудом подвергаются пересмотру в процессе изучения других языков. Например, слабая дифференцированность субкатегорий орудия, средства и способа действия, которые в русском языке единообразно выражаются творительным падежом, приводит к неразличению этих значений в интерязыке.

3. Интерферирующее воздействие ИЯ1 на ИЯ2 наблюдается на поверхностном уровне, т. е. затрагивает механизм выбора маркера инструментальных отношений. Искусственный мультилингв неосознанно находит эквивалентные маркеры в двух языках и абсолютизирует эту эквивалентность. Важность выявления «зеркальных» маркеров усиливается отсутствием дифференцирующего маркера в РЯ, в результате чего ИЯ1 становится формальной опорой для дифференциации. Но в связи с тем, что дифференциация останавливается на поверхностном уровне, вероятность ошибки очень велика, особенно в случаях нарушения «зеркальности».
4. В ситуации недостаточной дифференцированности инструментальных отношений в интерязыке по отношению к естественному языку усиливается роль отдельных маркеров, например, предлога par, который интуитивно воспринимается как более или менее полный эквивалент русского творительного падежа и как наиболее яркий маркер отношений инструментальности. Стремясь к наибольшей эксплицитности, интерязык создает конструкции, включающие предлог par, которые не существуют в естественном языке (*par faisant, * par faire qch).

5. Следует отметить, что в практике преподавания иностранных языков категории инструментальности не уделяется достаточного внимания, в отличие, например, от логических категорий (причины, следствия, уступки и т. д.) Это неудивительно, поскольку иностранный язык преподается, как правило, с опорой на текст, вне контакта с предметной реальностью и предметной деятельностью. В результате интерязык оказывается виртуальным конструктом, опирающимся в своем формировании на систему концептов РЯ и, в меньшей степени, ИЯ1. Поскольку радикально изменить эту ситуацию не представляется возможным, следует по крайней мере обратить внимание на формирование категории инструментальности в интерязыке обучающихся, учитывая единообразие выражения субкатегориальных значений в русском языке и опасность «зеркального» отображения способов передачи инструментальных значений, свойственных английскому языку.

\section{ЛИТЕРАТУРА}

1. Залевская А. А. Введение в психолингвистику. М. : Российск. гос. гуманит. ун-т, 1999. 382 с.

2. Золотова Г. А. Коммуникативные аспекты русского синтаксиса. М. : УРСС, 2003. 368 с.

3. Бондарко A. B. Теория значения в системе функциональной грамматики : на материале русского языка. М. : Языки славянской культуры, 2002. 736 с.

4. Лосева Н. В., Метельская Л. Н. Опыт экспериментального исследования межъязыковой интерференции в ситуации учебного мультилингвизма // Филология и культура. 2018. № 2 (52). С. 72-81.

5. Кобцева A. В. Категория инструментальности и способы ее экспликации в текстах газетно-публицистического стиля русского и немецкого языков : дис. ... канд. филол. наук. Ставрополь, 2006. 185 с.

6. Бужинский С. В. Семантика инструментальности в явной и скрытой грамматике (на материале русского и английского языков) : дис. ... канд. филол. наук. Курск, 2013. 294 c.

7. Вежбицка А. Дело о поверхностном падеже // Новое в зарубежной лингвистике. М. : Прогресс, 1985. Вып. 15. С. 303-341. 
8. Белошапкова В. А., Муравенко Е. В. Способы выражения инструментального значения в русском языке // Русский язык за рубежом. 1985. № 6. С. 78-83.

9. Тер-Авакян Г. А. Значение и употребление предлогов во французском языке. М. : Высшая школа, 1983. $240 \mathrm{c}$.

10. Гак В. Г. Теоретическая грамматика французского языка. Морфология. М. : Высшая школа, 1986. 312 с.

11. Гак В. Г. Сравнительная типология французского и русского языков. М. : Просвещение, 1983. 288 с.

\section{REFERENCES}

1. Zalevskaya A. A. Vvedenie v psikholingvistiku [Introduction to psycholinguistics]. Moscow: RGGU, 1999. 382 p.

2. Zolotova G. A. Kommunikativnye aspekty russkogo sintaksisa [Communication aspects of Russian syntax]. Moscow: URSS, 2003. 368 p.

3. Bondarko A. V. Teoriya znacheniya $v$ sisteme funktsional'noj grammatiki: Na materiale russkogo yazyka [The theory of meaning in the system of functional grammar: on the material of the Russian language]. Moscow: Yazyki slavyanskoj kultury, 2002. 736 p.

4. Loseva N. V., Metelskaya L. N. Opyt ehksperimental'nogo issledovaniya mezh"yazykovoj interferentsii $\mathrm{v}$ situatsii uchebnogo mul'tilingvizma [A case study on inter-linguistic interference in the conditions of studying multilinguism]. In Philology and Culture. 2018. No. 2 (52). Pp. 72-81.

Московский государственный институт международных отношений (университет) МИД России

Лосева Н. В., кандидат филологических наук, nрофессор

E-mail:natloseva@gmail.com

Брагина Т. В., старший преподаватель

E-mail:bragina_t@mail.ru

Поступила в редакциюю 20 января 2020 г.

Принята к публикации 25 март 2020 г.

\section{Для цитирования:}

Лосева Н. В., Брагина Т. В. Категория инструментальности в интерязыке (французском) искусственных мультилингвов // Вестник Воронежского государственного университета. Серия: Лингвистика и межкультурная коммуникация. 2020. № 2. C. 106-113. DOI: https:// doi.org/10.17308/lic.2020.2/2846
5. Kobtseva A. V. Kategoriya instrumental'nosti i sposoby ee ehksplikatsii $\mathrm{v}$ tekstakh gazetno-publitsisticheskogo stilya russkogo i nemetskogo yazykov [Instrument grammatical category in journalistic texts in Russian and German languages]. PhD Dissertation. Stavropol, 2006. $185 \mathrm{p}$.

6. Buzhinskij S. V. Semantika instrumental'nosti v yavnoj i skrytoj grammatike (na materiale russkogo i anglijskogo yazykov) [The Instrumental Meaning in Explicit and Implicit Grammar of Russian and English Languages]. PhD Dissertation. Kursk, 2013. 294 p.

7. Wierzbicka A. Delo o poverkhnostnom padezhe [The case for surface case]. Novoe v zarubezhnoj lingvistike. Moscow: Progress, 1985. Pp. 303-341.

8. Beloshapkova V. A., Muravenko E. V. Sposoby vyrazheniya instrumental'nogo znacheniya $v$ russkom yazyke [The Expression of Instrument Meaning in Russian ]. In Russkij yazyk za rubezhom. 1985. No. 6. Pp. 78-83.

9. Ter-Avakyan G. A. Znachenie i upotreblenie predlogov vo frantsuzskom yazyke [French Prepositions: their Semantics and Use]. Moscow: Vysshaya shkola, 1983. 240 p.

10. Gak V. G. Teoreticheskaya grammatika frantsuzskogo yazyka. Morfologiya [French Theoretical Grammar. Morphology]. Moscow: Vysshaya shkola, 1986. 312 p.

11. Gak V. G. Sravnitel'naya tipologiya frantsuzskogo i russkogo yazykov [Comparative Typology of French and Russian]. Moscow: Prosveshhenie, 1983. 288 p.

Moscow State Institute of International Relations Loseva N. V., Candidate of Philology, Professor E-mail: natloseva@gmail.com

Bragina T. V., Senior Lecturer

E-mail: bragina_t@mail.ru

Received: 20 January 2020

Accepted: 25 March 2020

\section{For citation:}

Loseva N. V., Bragina T. $V$. The category of instrumentality in french interlanguage of multiligual students. Proceedings of Voronezh State University. Series: Linguistics and Intercultural Communication. 2020. No. 2. Pp. 106-113. DOI: https://doi.org/10.17308/lic.2020.2/2846 